\title{
Crianças diagnosticadas com TEA na escola pública: novos desafios, velhas dicotomias
}

\author{
Marcos Cezar de Freitas ${ }^{1}$
}

Raelen Brandino Gonçalves ${ }^{2}$

\begin{abstract}
Resumo
Com base em pesquisas etnográficas em escolas públicas, repartições educacionais e equipamentos de saúde, este artigo aborda crianças diagnosticadas com Transtorno do Espectro do Autismo (TEA) em escolas públicas da cidade de São Paulo e Grande São Paulo. Questiona o modo como os direitos educacionais são reivindicados. Mostra com exemplos que garantir a presença da criança com TEA tem resultado numa busca por educação escolar que, contraditoriamente, prescinde dela. Reaparece a dicotomia entre educar e cuidar que outrora marcou o universo da educação infantil. É possível reconhecer que a identidade real de cada criança é substituída por uma identidade virtual, a dos laudos que têm sido buscados com intensidade. Categorias de Pierre Bourdieu, Richard Sennett e Erving Goffman foram usadas.
\end{abstract}

Palavras-chave: Autismo; TEA; Cuidar; Educar; Contradições.

\section{Children diagnosed with ASD in public schools: new challenges, old dichotomies}

\begin{abstract}
Based on ethnographic research in public schools, educational departments and health equipment, this article addresses children diagnosed with Autism Spectrum Disorder (ASD) in public schools in the city of São Paulo and Greater São Paulo. It questions the way in which educational rights are claimed. It shows with examples that guaranteeing the presence of the child with ASD has resulted in a search for school education that, contradictorily, dispenses with it. The dichotomy between education and care that once marked the universe of early childhood education reappears. It is possible to recognize that the real identity of each child is replaced by a virtual identity, from the reports that have been sought with intensity. Categories by Pierre Bourdieu, Richard Sennett and Erving Goffman were used.

Keywords: Autism; ASD; Caring; Educating; Contradictions.
\end{abstract}

\section{Introdução}

Este artigo formula algumas questões relacionadas à educação inclusiva no atual momento, especificamente com ênfase nas tensões que têm sido associadas à presença de crianças diagnosticadas com autismo ou Transtorno do Espectro do Autismo (TEA) nas classes comuns de escolas públicas ${ }^{3}$.

\footnotetext{
${ }^{1}$ Universidade Federal de São Paulo, Guarulhos, marcos.cezar@unifesp.br

2 Secretaria Municipal de Educação de São Paulo, São Paulo, raelen_9@yahoo.com.br

${ }^{3}$ Aqui se especifica "crianças", pois todas as pesquisas que deram base para este artigo acompanharam a situação de crianças da educação infantil ou do ensino fundamental.
} 
A hipótese, que permitiu a formulação das questões que serão apresentadas a seguir, retoma a dicotomia que deitou raízes, de modo muito prejudicial, na história da educação infantil brasileira, que é a (falsa) dicotomia entre educar e cuidar (FREITAS; BICCAS, 2009), supostamente deixada para trás após décadas de luta política, mas aparentemente atualizada no universo da escolarização de crianças referidas como "diagnosticadas".

Este texto é resultado e síntese de contínuos esforços etnográficos, com extenso material recolhido em muitos cadernos de campo. Por isso, algumas palavras são utilizadas com aspas, pois foram recolhidas dentro dos cenários de pesquisa e expressam o modo como emergiram.

As palavras entre aspas são fragmentos de entrevistas ou manifestações individuais que foram anotadas quando presenciávamos pessoas conversando a respeito das questões que são próximas ao universo de pesquisa aqui analisado. Aparecerão sempre sucedidas pela indicação de qual personagem produziu a frase destacada quando a autoria não estiver claramente identificável.

Perguntamos, após inúmeras etnografias realizadas em escolas públicas, em instâncias de governança educacional e em espaços de intersecção com profissionais da saúde (FREITAS; GARCIA, 2019; FREITAS; PRADO, 2017; GONÇALVES, 2019), se cotidianamente o modo de evocar direitos que nos últimos trinta anos configuraram o chamado público-alvo da educação especial ${ }^{4}$ não estaria, neste momento, engendrando uma contradição expressiva. Qual contradição?

A menção aos direitos educacionais relacionados à base legal construída para garantir o acesso à educação em classes comuns muitas vezes tem sido feita com premissas que, contraditoriamente, se baseiam no pressuposto de que a permanência não diz respeito à escolarização em curso, mas sim à garantia de acesso a cuidados justificados com aquilo que Martinez e Rey (2017) denominaram centralidade do laudo.

\footnotetext{
${ }^{4}$ A plataforma documental que configura especificamente esses direitos abrange: Diretrizes Nacionais para a Educação Especial na Educação Básica (BRASIL, 2001); Programa de Educação Inclusiva: direito à diversidade (BRASIL, 2003); Programa de Implementação de Salas de Recursos. Ministério da Educação. Secretaria de Educação Especial. Edital n.1, de 26 de abril de 2007. Programa de implantação de salas de recursos multifuncionais. Secretaria de Educação Especial. Edital n.1, de 26 de abril de 2007. Brasília, DF, 2007; Política Nacional de Educação Especial na Perspectiva da Educação Inclusiva (BRASIL, 2008b); Conselho Nacional de Educação, Câmara de Educação Básica Resolução CNE/CEB n.ㅇ 4, de 2 de outubro de 2009, Institui diretrizes operacionais para o atendimento educacional especializado na educação básica, modalidade educação especial. Diário Oficial da União, 5 de outubro de 2009. Diretrizes Operacionais para o AEE na Educação Básica (BRASIL, 2009b) e Decreto Presidencial № 7.612 de 17/11/2011 que institui o Plano Nacional dos Direitos da Pessoa com Deficiência: viver sem limites (BRASIL, 2011); Lei no 13.146, de 6 de julho de 2015. Dispõe sobre a Lei Brasileira de Inclusão da Pessoa com Deficiência, Câmara dos Deputados, DF, 2015.
} 
Estaria ocorrendo uma separação entre cuidar e educar, especialmente no bojo de situações mais complexas que demandam coadjuvantes como, por exemplo, cuidadores, estagiários, Auxiliares da Vida Escolar?

A categoria contradição é mobilizada aqui a partir de duas bases argumentativas importantes para os estudos relacionados ao tema inclusão. Com Sennett (2013) é possível refletir a respeito do enfraquecimento do impulso de cooperar com aqueles que se mantêm teimosamente outros. Ou seja, se é "como estranho" (MARTINEZ; REY, 2017) que foi dado o acesso, é como estranho que alguns logram permanecer. Com Bourdieu (2005) é possível compreender que há modos de entrar que garantem a permanente impermanência, materializada num lugar para (não) estar, em que encontramos os "excluídos no interior".

Em outras palavras, estamos formulando questões, não somente às pessoas, mas ao contexto em si, porque os cenários pesquisados e as cenas observadas dão visibilidade à contradição presente num modo de argumentar o direito à educação prescindindo dela.

Outra indagação é formulada com base na distinção que Erving Goffman (2010, 2011, 2012) fez entre identidade real e identidade virtual. A escuta de professores, pais, profissionais da saúde que as pesquisas aqui mencionadas ensejaram, instalou uma questão de fundo todas as vezes que essas personagens manifestaram expectativas de escolarização das crianças diagnosticadas com as quais se relacionavam.

A questão adquiriu o seguinte contorno: nossas(os) interlocutoras(es) estavam mencionando a criança ou o autismo? Estavam aludindo à personagem narrada no laudo ou à criança real que representavam quando afirmavam que "sem certos cuidados o impossível fica mais impossível ainda"? (Professora do Ensino Fundamental).

Em certas circunstâncias, algumas personagens que participaram das pesquisas mencionaram a escassez de estudos a respeito, em regra indisponíveis para a escola. De fato, essa escassez não se comprova, por isso, aproveitaremos a oportunidade para indicar, ainda que parcialmente, o que tem sido produzido academicamente a respeito.

Porém, mais do que inventariar o que o trabalho acadêmico tem construído em termos de educação de pessoas com autismo ou TEA, o objetivo central que organiza a exposição de argumentos a seguir diz respeito à apropriação do tema, no sentido que Certeau (2000) confere ao movimento de apropriar-se. Trata-se da apropriação que se mostra exatamente nos 
momentos em que são demandados direitos educacionais e, simultaneamente, são reclamados saberes específicos para o enfrentamento das demandas implicadas na perspectiva da educação inclusiva. Por isso, o percurso para sistematizar as respostas às questões aqui formuladas tem início na análise sobre o encontro entre os temas autismo, escola e judicialização.

\section{Uma judicialização vulnerável a dicotomias}

No bojo de uma pesquisa sobre a percepção da diversidade atualmente presente no universo da educação pública nas cidades de São Paulo e Guarulhos (FREITAS, 2017) foi possível registrar situações muito complexas. Muitas vezes ficou claro que as instâncias de governança das Diretorias Regionais de Educação têm sido pressionadas a reconhecer direitos advindos da indicação pericial, um laudo, que permite reclamar especificidades correlatas às deficiências.

Esta pesquisa entrevistou autoridades educacionais, gestores e coordenadores identificados previamente como responsáveis diretos ou indiretos pelo atendimento de demandas de acessibilidade e inclusão. Todas as entrevistas ocorreram nos próprios equipamentos de gestão educacional e, inúmeras vezes, foi utilizada a técnica de Lahire (2000) que sugere entrevistar e, após um intervalo de tempo, voltar a entrevistar para verificar se os interlocutores mantêm as perspectivas apontadas nos encontros iniciais.

Essa dinâmica de permanecer em equipamentos de gestão educacional e entrevistar seus protagonistas também permitiu levar a efeito aquilo que tem sido denominado etnografia de documentos (FERREIRA; LOWENKRON, 2020). Ou seja, foi possível registrar a dinâmica com a qual a pessoa entrevistada demonstra a materialidade de suas informações e como, ali no microcosmos burocrático em que se insere, é organizado o "modo de localizar" (Gestora de Instância de Secretaria de Educação) os "fios da meada" (Supervisora Educacional) de determinados problemas.

Na cidade de São Paulo, as Diretorias Regionais de Educação (DREs) estão conectadas à Secretaria Municipal de Educação de São Paulo (SMESP). Abrigam em suas estruturas de trabalho uma vinculação explícita à formação em educação inclusiva mediada pelo Centro de Formação e Acompanhamento à Inclusão (CEFAI) de cada DRE, e respondem pelo dinamismo da Coordenação Pedagógica que emana da SMESP, proporcionando apoios à aprendizagem. 
As mediações de apoio se materializam na possibilidade de solicitar Auxiliares da Vida Escolar (AVE), ações do Núcleo de Apoio e Acompanhamento para Aprendizagem (NAAPA) ou Atendimento Educacional Especializado (AEE) em Sala de Recursos Multifuncionais (SRMs).

Tomando por exemplo a DRE Itaquera, mencionada aqui por sua expressiva base territorial ${ }^{5}$, é possível constatar que seu CEFAI intensificou significativamente nos últimos anos a rotina de responder a demandas judiciais.

Tanto isso se estabilizou como rotina, que há formulários muito detalhados, cuidadosamente preenchidos em que se destacam na base remissiva indexadores como: procedimento ordinário mediante requisição de tratamento médico, psicológico ou psiquiátrico, em regime hospitalar ou ambulatorial.

A análise dessa base documental fornece exemplos importantes para o que se discute neste artigo. Podemos citar uma petição derivada de um processo aberto no Foro Regional de Itaquera da Comarca da Capital de São Paulo, que requer atendimento psicopedagógico para a criança mencionada nos autos, representada por seus pais.

Para a DRE torna-se necessário argumentar detalhadamente que a Secretaria, como um todo, trabalha com base na Política Nacional de Educação Especial na Perspectiva da Educação Inclusiva (2008b) e que reconhece as bases argumentativas da Declaração de Salamanca (1994) que aponta a escola regular como lócus para promover a educação inclusiva.

São recuperados trechos da Convenção da ONU (2006) sobre os Direitos das Pessoas com Deficiência e a resposta institucional se antecipa lembrando que há respeito constitucional às pessoas com deficiência e acatamento às diretrizes derivadas de Decretos Legislativo (BRASIL, 2008b) e Executivo (BRASIL, 2009a) que estabeleceram consequências legais aos signatários da Convenção.

A autoridade educacional elucida à autoridade judiciária que há pareceres produzidos no Conselho Nacional de Educação (CNE/CEB no 4, 2009) e decretos e portarias do Poder Executivo local que detalham procedimentos e obrigações relacionadas às matrículas de crianças com deficiências, transtornos globais do desenvolvimento e altas habilidades e explica que a DRE defende o Atendimento Educacional Especializado como articulador dos trabalhos pedagógicos que permeiam a vida escolar dessas(es) alunas(os).

\footnotetext{
${ }^{5}$ Abrangendo os subdistritos Carmo, José Bonifácio, Itaquera, Cidade Líder, Carrão, Aricanduva e Formosa.
} 
A criança em questão tem apoio de uma Professora de Atendimento Educacional Especializado (PAEE) e essa profissional faz a articulação com famílias e parcerias para o atendimento do público-alvo. Essa PAEE faz o Atendimento Educacional Especializado (AEE) de todos os que necessitam e elabora um plano individualizado.

Explica para a autoridade que a questiona que a AVE é prerrogativa de alunos cuja autonomia para higiene, locomoção e alimentação está comprometida e que no caso da Unidade Escolar em questão somente duas crianças demandam esse serviço, proporcionando, portanto, "um atendimento intensivo". Informa também a presença de três estagiários e que um deles acompanha especificamente a criança mencionada no processo.

A argumentação da autoridade judiciária evoca a Lei do Estado de São Paulo no 12.524 de 2007 (SÃO PAULO, 2007) e a Lei do Distrito Federal no 4095 de 2008 (BRASIL, 2008a) que asseguram direitos psicopedagógicos a estudantes com dislexia.

Os exemplos arrolados pela autoridade educacional permitiram responder que a referência à dislexia não faz parte dos direitos adquiridos pelo público-alvo da educação especial e que a escola não pode confundir deficiências com os chamados transtornos de aprendizagem.

Freitas e Garcia (2019) analisaram a ampla presença de argumentos baseados em laudos em muitas experiências de escolarização, e localizaram situações em que embates entre famílias e escolas reforçavam a percepção crescente de que as deficiências têm bases mais vantajosas de direitos educacionais consolidados. São situações distintas, mas com aspectos análogos. A autoridade educacional que foi uma das personagens dessa trama, cujo enredo interpelou uma escola pública, ressaltou sua participação em quinze processos com o mesmo pedido. Esses processos igualmente naturalizavam a dificuldade de aprendizagem como se fosse um transtorno e faziam dessa patologização um ponto de acesso à equiparação com a situação de pessoas com deficiência. Isso indica certa generalização de um modo de pensar que tem potencial para descaracterizar direitos de acessibilidade e inclusão arduamente conquistados.

\section{Da construção multifacetada do tema}

Foi possível vislumbrar aspectos muitos específicos no modo de reivindicar atendimento especializado, reinvindicações que se ampliavam em direção aos coadjuvantes que têm 
participado do trabalho educacional escolar. E a aproximação possibilitou também observar pais de crianças diagnosticadas que argumentavam de modo pendular. Ou seja, exigiam que a escola garantisse direitos "derivados do diagnóstico" (Pai de aluno), mas, por outro lado, também queriam impedir que a escola interrompesse ou "atrapalhasse" (Mãe de aluna) os serviços obtidos junto aos planos de saúde que tinham sido interpelados pelos familiares com outras dinâmicas de judicialização.

Familiares se amparam na Lei 12.764/2012 (BRASIL, 2012) conhecida como Lei Berenice Piana, em homenagem a uma mãe que, desde que recebeu o diagnóstico de seu filho, lutou pelos direitos das pessoas com autismo. Essa lei passou a considerar a pessoa com diagnóstico de autismo ou TEA, pessoa com deficiência para todos os efeitos legais.

O fato é que a escola pública tem lidado com embates que abrangem reivindicações por acesso a fármacos e tem reagido ininterruptamente às apropriações imprecisas como, por exemplo, a suposição constante, no plano cotidiano, de que comportamentos disruptivos têm algo a ver com o autismo. Dissemina-se aceleradamente a impressão de que muitos alunos estariam "pelo menos dentro de algum lugar" (Professora Educação Infantil) caracterizado na (im)precisão de um espectro, o TEA.

O manejo de palavras e siglas, a preferência por autismo ou TEA, já faz parte do dia a dia da educação pública, pelo menos nas cidades aqui pesquisadas. São imprecisões, mas que, por isso mesmo, corroboram o importante trabalho elaborado por Luz (2018) que verificou a consolidação de preferências no modo de referir a questão.

A pesquisadora, em sua síntese, demonstrou que na veiculação da produção científica sobre o autismo no Brasil, a terminologia TEA surgiu pela primeira vez em 2003. Observou que no período de 2003 a 2009, ocorreu uma pequena adesão ao uso da sigla TEA, mas de maneira residual quando comparada à utilização da palavra autismo. Entre 2010 e 2015, "ficou mais evidente a adesão gradativa do meio acadêmico à utilização do termo TEA, foram 21 artigos contra 48 que usaram o termo autismo" (LUZ, 2018, p.525). As famílias têm reivindicado atenção mencionando predominantemente o TEA, ou misturando: "meu filho é autista porque tem TEA" (Mãe de aluno).

Lima e Laplane (2016) fizeram importante levantamento em escolas públicas do interior do Estado de São Paulo. Como, desde 2009, Autismo, Síndrome de Asperger, Síndrome de Rett 
e Transtornos Desintegrativos da Infância substituíram Transtorno Geral do Desenvolvimento nos dados do Censo Escolar, as autoras procuraram por trajetórias escolares e concluíram que a escolarização de alunos identificados com autismo tem sido interrompida constantemente, raramente se completando ou chegando ao ensino médio (LIMA; LAPLANE, 2016).

Sobre os esforços para definir essa presença, as autoras destacaram que:

Em 2013, a American Psychiatric Association (APA) propôs a adoção de uma nova terminologia para os antes denominados transtornos globais do desenvolvimento, DSM IV (...) agora conhecidos como transtorno do espectro do autismo. A nova denominação corresponde a uma mudança na conceituação do transtorno, que reduz os três domínios anteriormente considerados (prejuízo qualitativo na interação social, na comunicação e padrões restritivos e repetitivos de comportamento, interesses e atividades) para dois: déficits sociais e de comunicação e interesses fixados e repetitivos. Essa mudança tem por objetivo facilitar o diagnóstico e situar numa linha contínua traços ou características distribuídos em níveis de severidade para auxiliar a provisão dos apoios necessários para o desenvolvimento (LIMA; LAPLANE, 2016, p.270).

O autismo tem sido estudado no âmbito acadêmico e não exclusivamente pelas áreas médicas, como apontou o levantamento que fizemos no banco de teses e dissertações Capes.

Ao digitar o descritor "autismo", percebe-se que a palavra-chave aparece 1.161 vezes no banco de teses e dissertações da Capes. Restringindo a busca para o âmbito dos Programas de Pós-Graduação em Educação, este número se reduz a 158 pesquisas, entre elas: 126 dissertações e 32 teses defendidas no período de 1995 a 2017, com uma concentração de maior número de pesquisas em 2017, que totalizou 24.

No movimento de volta ao chão da escola desta pesquisa foi possível perceber ansiedade generalizada para se obter um laudo e, principalmente, perceber como professores estão submergindo numa situação cada vez mais aparatada com instâncias de auxílio, mas, paradoxalmente, cada vez menos educacional.

A requisição da $\mathrm{AVE}$, por exemplo, tem sido considerada pré-requisito para a educação escolar dessas crianças. Ao mesmo tempo, são muitos os protagonistas desse cotidiano que alertam para o risco da criança ser considerada responsabilidade exclusiva da AVE, de modo que ambas(os), alun(a)o e auxiliar, frequentemente também submergem numa lógica que transforma o substantivo "inclusão" num advérbio de tempo, ou seja, n'algo que se dá entrementes, enquanto a educação acontece, nesse ínterim, situação em que alguém se ocupa 
da criança "para que as demais estudem" (Avó de aluna).

Como as lutas familiares não se restringem ao universo escolar, os efeitos resultantes dos ganhos impostos judicialmente aos planos de saúde, por exemplo, concedem à criança acesso ao Auxiliar Terapêutico (AT).

Não são poucas as ocasiões nas quais é possível encontrar o AT dentro da escola e essa presença seguidamente inibe a ação professoral, uma vez que o profissional em questão, antes de tudo, é uma salvaguarda para que a escola "não desmanche o que tem sido obtido com as terapias" (Mãe de criança da Educação Infantil).

Os ATs representam uma expertise externa ao professor, expertise essa reconhecida como distante dos saberes pedagógicos. O AT "sabe o que é o autismo" e conhece as "particularidades do TEA" (Pai e Mãe de aluna).

Por isso, respaldam pedidos familiares para que a criança tenha sua jornada escolar reduzida e defendem que o essencial é o que está acontecendo no plano terapêutico, em que se dá o trabalho com o Applied Behavior Analysis (ABA), cujo uso diz respeito a um universo de comercialização de cursos, especializações e adesões a pacotes propostos em sites especializados; uma dinâmica de profunda mercantilização.

Uma autoridade educacional entrevistada narrou o episódio em que se deparou com uma AT usando uva passa como reforço comportamental a uma criança diagnosticada, matriculada numa escola sob sua jurisdição educacional.

Muitos pais têm sido convencidos da imprescindibilidade do método ABA e isso reforça o contato direto entre famílias e empresas especializadas, sem a mediação da escola, mas com reflexos diretos no seu dia a dia.

\section{De volta às dicotomias}

Parte desse processo se reveste de justificativas que muitas vezes tensionam o cenário de aprendizagem, com suas múltiplas e sobrepostas cenas (GOFFMAN, 2011). Isso porque se naturaliza com frequência a percepção de que a educação inclusiva é um "externo interno", ou seja, uma percepção de que a criança com deficiência não faz parte completamente do processo, podendo interrompê-lo com suas demandas consideradas mais afeitas às mãos cuidadoras. $E$, 
nesse contexto, há modos cotidianos de legitimação e deslegitimação da própria noção de público-alvo.

Um gestor de Secretaria Municipal de Educação da Grande São Paulo confidenciou que professor(as)es seguidas vezes manifestavam descontentamento com aquilo que consideravam ser "excessivo para a escola" (Gestor de Divisão Educacional). Autismo e TEA são os mais mencionados nessas representações de excesso.

Quando em 2008 a Política Nacional de Educação Especial tornou-se a Política Nacional de Educação Especial na Perspectiva da Educação Inclusiva, o modo de debater "público-alvo" foi adensado conceitualmente. Reconhecia-se que inclusão deve exceder a delimitação das deficiências, abrangendo questões de classe social, de gênero, raça, etnia tornando-se, a deficiência, categoria transversal a todas as intersecções que configuram a experiência de cada um(a). Mas isso parece distante da experiência da pessoa diagnosticada com TEA.

Seria a personagem do TEA uma espécie de corpo estranho inclusive entre os que se esforçavam por delinear e garantir ações inclusivas baseadas no adensamento das ações escolares e da formação de professoras(es)?

Um exemplo concreto dessa complexidade pode ser identificado no mesmo ano de 2008, quando foi publicado o conjunto das mais significativas produções do II Congresso de Educação Especial, realizado na Universidade Federal de São Carlos.

Com o título "Temas em educação especial: múltiplos olhares" organizado por Almeida, Mendes e Hayashi (2008) e apoio da CAPES com Programa de Apoio à Educação Especial $(\mathrm{PROESP})^{6}$, foi apresentado um mosaico importante para vislumbrarmos as múltiplas faces do trabalho acadêmico que, naquele momento, abordava o tema inclusão e suas repercussões na educação especial e no universo escolar.

Mais de 400 trabalhos foram apresentados e, dentre estes, 147 foram indicados com potencial de publicação, posteriormente sendo aprovados 81 trabalhos.

Foram divulgadas as tendências expressas na produção científica, nas políticas públicas, na formação de professores, no ensino colaborativo. Foram abordadas as representações sociais da deficiência presentes na formação docente. Foram analisados os eufemismos que se referem

\footnotetext{
${ }^{6}$ Este evento foi um marco, considerando a visibilidade que proporcionou aos muitos grupos de pesquisa e seus objetos em Educação Especial. A coletânea Temas em educação especial: múltiplos olhares, publicada em 2008 tornou-se num registro de referência, apoiado, inclusive pela agência maior da pós-graduação que é a CAPES.
}

Periódico Horizontes - USF - Itatiba, SP - Brasil - e021018 
aos alunos "com necessidades especiais". Foram arroladas as dificuldades relacionadas à permanência e preparação dos professores.

Essas questões se desdobraram em debates específicos sobre a ética nos estudos de inclusão; sobre a interface com familiares de crianças com necessidades especiais; sobre potenciais contribuições das chamadas habilidades sociais para a educação especial; sobre o desafio das chamadas altas habilidades.

Foram consideradas as possibilidades da tecnologia assistiva, da terapia ocupacional, dos suportes à escolarização e até o papel da iniciação científica no futuro das práticas inclusivas. O TEA foi mencionado naquele contexto tomando por base as dificuldades presentes nos "aspectos comunicativos". O TEA, portanto, foi abordado ligeiramente, como expressão de restrições comunicativas num todo voltado para a presença de pessoas com deficiência em contextos escolares.

Contraditoriamente, muitos argumentos relacionados ao tema renovam a dicotomia entre educar e cuidar apresentando as premissas da particularidade orgânica, mas também exigindo atenção ao pressuposto de que "cada criança é única". A evocação do corpo universal que caracteriza a narrativa médica (CANGUILLEM, 2000) colide com a defesa do corpo concreto daquela(e) que tem nome, origem, classe social, raça, etnia, gênero e que efetivamente está matriculada(o) na escola.

Para nos certificarmos que nossa percepção não estava enviesada porque formada na coleta de dados em espaços de governança educacional e gestão pública, também levamos a efeito a observação e diálogos com protagonistas do cotidiano escolar, interagindo com professoras(res) e familiares dentro de duas escolas públicas.

Essas escolas foram escolhidas porque ostentavam o maior número de matrículas de crianças diagnosticadas com TEA e proporcionavam também observar a transição da educação infantil para a fundamental. Para além disso, a situação favorecia manter contato com profissionais da saúde que atenderam as crianças sobre as quais dialogávamos.

\section{No enquadramento da vida escolar}

As crianças que serão aqui mencionadas ${ }^{7}$ estavam matriculadas inicialmente na escola 1 ,

\footnotetext{
7 O Comitê de Ética em Pesquisa da Instituição acompanhou e aprovou os procedimentos de pesquisa que se aproximaram das crianças mencionadas. Processo CEP/Unifesp № 2.197.095.
}

Periódico Horizontes - USF - Itatiba, SP - Brasil - e021018 
que será denominada "Escola Aprender". No fim do ano letivo de 2017 todos ingressaram no primeiro ano, permanecendo duas na mesma escola, duas matriculadas na escola 2, que será denominada "Escola Conhecer" e outra na escola 3 que será chamada "Escola Integral" por apresentar essa modalidade de jornada para crianças do 4 ㅇ e 5o ano. As escolas estão num município da chamada Grande São Paulo.

Foram realizadas entrevistas em três etapas, com pais ou responsáveis e também professoras(es) e profissionais da saúde. Tanto professoras(es) como profissionais da saúde foram abordadas(os) mais de uma vez. Essas entrevistas ocorrem nas dependências das escolas. Após a primeira entrevista com os pais, foram identificados profissionais da saúde que estavam relacionados com a educação escolar daquelas crianças, fosse pela produção do diagnóstico, fosse pelo acompanhamento clínico e terapêutico. Foram identificadas e entrevistadas uma neurologista, uma fisioterapeuta, uma fonoaudióloga e uma psicóloga, que nos receberam em seus locais de atendimento.

Essa aproximação da lupa para discutir a matrícula de crianças diagnosticadas com TEA não foi, de modo algum, inédita.

Já nos referimos a Lima e Laplane (2016) que abordaram o interior do Estado de São Paulo, mas temos também Gomes e Mendes (2010) que caracterizaram os alunos com autismo matriculados em escolas municipais regulares de Belo Horizonte e descreveram como essa dinâmica de escolarização vem ocorrendo a partir da perspectiva de seus professores (GOMES; MENDES, 2010). Pesquisas semelhantes, igualmente densas, estão presentes nos registros de muitos Programas de Pós-Graduação, em diversos Estados como, por exemplo, as teses de Alves (2014), Barreto (2016) e Melo (2010).

Lopez (2011) investigou como no processo de escolarização alunas(os)os com TEA contextualizam a informação. Neves, Antonelli, Silva e Capellini (2014) mapearam a produção acadêmica nacional disponível no Banco de Teses e Dissertações da CAPES, procurando dimensões curriculares na escolarização formal de alunas(os) com o mesmo diagnóstico.

Ou seja, não estamos apresentando uma incursão no tema que sequer possa aventar originalidade. Todavia, nossa intenção ao adentrarmos escolas públicas e equipamentos de gestão e saúde, como afirmamos ao início, é a de acrescentar a esse universo de análise as contradições sobre as quais indagamos, desdobrando em investigação concreta a hipótese de 
que a educação inclusiva de crianças com autismo ou TEA esteja operando um modo de reivindicar direitos que relativiza o alcance efetivamente educacional da demanda, possivelmente confundindo a identidade real das crianças com uma identidade virtual produzida com repertórios clínicos.

Para os profissionais da saúde foram elaborados roteiros com descrições sobre o cotidiano daquelas crianças na escola, de modo a favorecer a verbalização de opiniões com base nas narrativas escolares e familiares. As crianças não foram abordadas diretamente.

\section{Interlocuções e registros}

A entrada na Escola Aprender propiciou o primeiro contato com os familiares e professores das crianças que tinham o diagnóstico ou aquilo que a escola denominava "suspeita de autismo" (Professora).

A categoria expectativa, trazida por nós aos encontros, cuja pauta para o diálogo era o que se esperava dessas presenças complexas na escola, vem de Goffman $(2010,2011)$ que demonstrou como aquilo que se espera de alguém tem potencial para ocupar o próprio lugar dessa pessoa.

Os pais que já contavam com o diagnóstico ou os que o aguardavam compartilhavam memórias de angústias acumuladas ao redor da questão.

Aqui nos reportamos às histórias de Pedro, Heitor, Beatriz, Matheus e Lucas (nomes fictícios). Isso é necessário para completar esta análise com experiências concretas, derivadas do diagnóstico, e registrar expectativas de escolarização construídas no contexto atual.

Tomemos atenção a alguns aspectos específicos.

Sobre tornar-se coadjuvante da professora:

Quando eu vim e conversei com a secretaria daqui, eu ainda não tinha um diagnóstico fechado, era um diagnóstico aberto. No primeiro dia ele entrou com a professora, sozinho, aí depois no término da aula, eu fui conversei com ela, aí ela perguntou se eu poderia ficar com ela, no caso como ele não tem um laudo, aí não tem ninguém pra ficar com ele né, uma cuidadora [...] (Mãe de Pedro). 
Sobre a confirmação:

[...] eu saí chorando da sala dela, aí veio uma pedagoga lá da secretaria da saúde, e conversou comigo, me interrogou, e depois foi observar a criança na sala e depois de alguns meses, ele foi chamado pra fazer a triagem na escola especial. [...] a neuro lá da escola especial, que ele passa com ela lá, deu a conclusão de autismo [...] foi concluído, ele tem laudo, tem tudo né, fez exame (Mãe do aluno Lucas).

O rótulo TEA se faz acompanhar de um repertório de palavras que gradativamente são incorporadas ao modo como as pessoas participam das interações com a criança e seus familiares. E em muitas situações a condição da criança é considerada inexprimível ou não classificável e noutras, paradoxalmente, muitos se sentem à vontade para ajuizar a "veracidade" do comportamento identificado no laudo.

Na Escola Aprender, registramos percepções de docentes da educação infantil sobre a presença dessas crianças:

Como foi pra você saber que receberia um aluno com diagnóstico de autismo? Professora de Lucas: Pra mim foi tranquilo, não tive assim nenhum tipo de problema, o ano passado eu também trabalhei com uma criança autista e também não tive medo, pra mim isso é um desafio. Eu procurei primeiramente ler bastante sobre o assunto, como se procedia, como que era o comportamento dessas crianças, é claro que uma criança é diferente da outra, nunca é igual, nem os nossos, aqui, um ou outro, eles são diferentes, então eu não tive medo não.

Professora de Beatriz: Olha, eu nunca tinha trabalhado com uma criança com autismo, então quando eu fiquei sabendo [...] uma professora já me deu todas as características, falou que ela bate, ela grita o tempo inteiro e aí eu fiquei meio apavorada, porque eu recebi e já fiquei sabendo e fiquei me imaginando apanhando da criança e a criança gritando o tempo inteiro, mas assim foi muito mais tranquilo do que eu imaginava [...].

Professor de Heitor: Na verdade como eu sempre atuei na área pública, em escolas públicas, não teve nenhum sintoma de surpresa na verdade, porque desde que eu ingressei na prefeitura eu sempre trabalhei com a questão da inclusão [...], eu busquei questões a respeito, estudos a respeito da Síndrome de Asperger, por exemplo, vi trabalhos anteriores das outras professoras, então foi bem tranquilo.

Professora de Pedro: Não, na verdade nem tive informação nenhuma, no dia foi uma surpresa mesmo, surpresa [...] ele estava passando em psicólogo [...] e estava sobre investigação de autismo, ela disse que avisou a escola, mas a escola não me passou nada [hoje] ele é um aluno como qualquer outro [...] eu trabalho diferenciado com ele. 
Professora de Matheus: É um pouco impactante, eu fiquei assim receosa porque eu já peguei outras inclusões, mas nunca um autista [...] e assim que eu soube já comecei a pesquisar o portfólio da professora do ano passado.

Essa manifestação da Professora de Matheus tem grande importância para a análise em andamento neste artigo. O que chama atenção nessas manifestações é outro argumento pendular, pois alguns se explicaram indicando que procuraram conhecer a criança em questão, mas, predominantemente, as respostas indicaram a busca de informações a respeito de "sintomas", "tendências", "riscos", "impossibilidades" contidos na descrição do TEA, independentemente da criança a ser recebida. Há diferença substantiva quando as expectativas incidem sobre a criança ou quando derivam "daquilo que se sabe sobre o TEA".

A mãe de Heitor, por exemplo, diversas vezes indicou que esperava que seu filho fosse alfabetizado, ainda que "quieto no mundo dele". Já a mãe de Pedro manifestou expectativa de "sair de cena", ou seja, que pudesse ser substituída da condição de auxiliar que estava desempenhando por um "professor específico para ele". Esse "professor específico", conhecendo o "TEA como ele é", na verdade significava a esperança de receber um cuidador ou auxiliar. Na Rede Pública pesquisada, esse direito diz respeito a atender crianças quanto a alimentação e higienização, além disso, quando necessário, são solicitados especificamente para acompanhar a criança em sala de aula.

Não podemos desconsiderar que a mãe "aguardava uma professora" como se o aluno ainda não contasse exatamente com uma. A "professora de autistas" (Mãe de Beatriz) tornavase, no bojo da expectativa, aquela que faltava, ou seja, aquela que a legislação denomina cuidadora, porque não há em nenhum dispositivo jurídico brasileiro qualquer possibilidade para considerar a hipótese de uma sala de aula contar com mais de um professor em decorrência de complexidades específicas. O profissional aguardado só poderia ser um não professor.

O cuidador era aguardado também porque sua presença, por suposto, colaboraria com a resolução de problemas concretos. A soma de estratégias entre professor e cuidador poderia render resultados comemorados em família. Um pai, por exemplo, manifestou satisfação à medida que a escola proporcionou a seu filho autonomia para utilizar o banheiro.

A professora de Pedro destacou que esperava dele o mesmo que esperava das demais crianças. Já a professora de Lucas esperava que ao final do ano seguinte ele estivesse "ao menos 
alfabético", pois essa era a expectativa da Secretaria de Educação.

Mas, de modo geral, as falas reiteravam aquilo que a Professora de Matheus expressou de modo muito objetivo: "[...] minha expectativa é que, no próximo ano, eles consigam um cuidador para ele"

\section{Profissionais da saúde entram em cena}

Há uma escola especializada nas imediações que oferece atendimento em contraturno aos alunos matriculados no Município. Lá, foram entrevistadas uma psicóloga, uma fonoaudióloga e uma fisioterapeuta. A neurologista dessas crianças foi entrevistada em sua clínica particular, pois se desvinculou dessa escola especializada. O que conectou essas crianças a esses profissionais foi a produção de um laudo ou a decorrência de seu conteúdo.

Essas profissionais, com base no repertório de suas especialidades, reagiam às informações sobre o andamento das atividades escolares com percepções de evolução no quadro e prescrição de parceria entre família e escola. A psicóloga, por exemplo, destacava o "cuidador como aporte necessário ao professor".

A fonoaudióloga também reforçou o caráter estratégico da parceria entre família e escola, indicando também, conforme a particularidade dos casos, a importância de outros profissionais. Em termos concretos, essa alusão a outros profissionais abria espaço na argumentação para a defesa do "uso de medicação", tendo em vista a "necessidade de atenuar certos comportamentos apresentados". Indicava um critério de avaliação, modulado pela "observação de pequenos avanços".

Já a fisioterapeuta destacava os benefícios de "estar na escola" Considerando inclusive que a instituição era a mediadora necessária para que fosse possível "receber atendimento".

A neurologista destacava a importância da escola especializada para a criança, considerada mais adequada para "oferta de atenção individualizada". Destacava o direito a um auxiliar em sala de aula e ampliava a expectativa de direitos baseando o argumento na "necessidade de equipes multiprofissionais".

Quando alguns exemplos vieram à tona, a psicóloga também indicou que a aprendizagem em questão dependeria de medicação, pois "se o sintoma não estiver sob controle há dificuldade 
no processo da aprendizagem".

A figura do auxiliar foi mencionada como necessária para "observar e identificar o desenvolvimento" em termos de desempenho e a partir de um argumento que também utilizava o desempenho como categoria, a fonoaudióloga endossou a utilização do ABA.

Essas profissionais, com diferentes ênfases, mencionaram o medicamento como "auxiliar do professor em termos comportamentais".

Enquanto a fisioterapeuta mencionava a idade da criança como fator fundamental a ser considerado nas estratégias de vinculação às tarefas, a neurologista propunha um "investimento naquilo que a criança vai bem", incentivando o uso da medicação para melhorar o comportamento.

A psicóloga reprovava a presença da mãe substituindo a auxiliar, afirmando ser fundamental nessa nova dinâmica de socialização consolidar a diferenciação em relação ao núcleo familiar. A fisioterapeuta concordou com esse argumento. Já a neurologista considerou arriscado "tirar a mãe" da sala de aula. Entre concordâncias e discordâncias, a estereotipia foi tema recorrente e a dificuldade da família em aceitar o laudo também.

\section{No ensino fundamental}

Essas crianças ingressaram no ensino fundamental. Os alunos Lucas e Heitor permaneceram no mesmo ambiente escolar que é a Escola Aprender, já os alunos Pedro e Matheus foram para a Escola Conhecer e a aluna Beatriz para a Escola Integral.

Na transição, o pai de Matheus indicou que sua maior expectativa em relação ao ensino fundamental era "conseguir finalmente a cuidadora". O pai de Heitor corroborou a expectativa de contar com a presença da cuidadora, mas associou essa presença à possibilidade de aprender a ler e escrever, relativizando o alcance do trabalho docente, ainda que o elogiasse.

A expectativa com a chegada de um apoio e a comparação com os outros foram configurando o quadro do que se esperava da escola e na escola. A mãe de Lucas esperava que ele escrevesse no ritmo da progressão escolar, ou seja, no "compasso" do trabalho que todos faziam. Esse "fazer como todos fazem" foi retomado em nossos diálogos posteriores.

Com o passar do tempo a mãe de Pedro indicava que havia permanecido ajudando a 
professora e, por isso, considerava que a "ausência de progresso" ainda se dava porque seu filho não havia recebido "a professora dele". Asseverava: "sou mãe, não professora"!

Os pais convergiam no entendimento da palavra inclusão. Inclusão era tomada como sinônimo de convivência, antípoda dos cantos de isolamento que "caracterizam toda criança autista" (panfleto de divulgação da ABA).

Mas a mãe de Lucas se queixava que seu filho estava dentro, mas não estava incluído. Ao ser estimulada a aprofundar sua opinião, respondeu que a criança não estava incluída porque "ainda não tinha recebido seu cuidador".

As famílias manifestavam com grande ênfase a percepção que tinham a respeito do papel mediador da escola na obtenção dos laudos. Se os laudos são essenciais para o acesso a direitos que assistem a pessoa descrita no TEA, a escola seria a narradora por excelência, capacitada a reunir os exemplos que, de posse dos clínicos, se tornariam saberes periciais identificadores do que a pessoa (não) é.

A professora de Beatriz, nesse novo ciclo, destacou a importância fundamental do profissional de saúde e do acesso aos "medicamentos para autistas". Outra professora que também acompanhou noutro contexto a mesma turma de Beatriz acrescentou que sua maior expectativa era a de que a criança fosse autônoma, cuidasse de si sem o cuidador.

Nesse caso, há uma particularidade de gênero a registrar, pois quando Beatriz finalmente recebeu um cuidador, a família solicitou a troca por uma cuidadora, e foi atendida.

Quando a professora foi indagada sobre Heitor, considerou pouco provável e difícil seu desenvolvimento, uma vez que sem cuidador específico para ele (tinha acesso compartilhado com outra criança e a profissional em questão estava em vias de licenciar-se), era necessário mobilizar a mãe para auxiliar a escola. Mantinha aberta pequena esperança de avanço na escolarização, mas destacava com ênfase que "com o cuidador a evolução seria maior".

Na Escola Conhecer a professora de Pedro manifestou expectativa de alfabetizá-lo e pormenorizava o passo a passo que caracterizava seu envolvimento com a "especificidade do caso". Mas em relação ao mesmo processo, na mesma escola, a professora de Matheus argumentava que um "atendimento só para ele seria mais adequado".

Quando essa professora se aposentou, sua substituta (que tardou a assumir) assegurou que estava "estudando as etapas do autismo". E isso, no conjunto das falas, reiterava a nossa 
percepção de que em nenhuma circunstância nos deparávamos com argumentos que indicassem a busca por fundamentação pedagógica mais adequada, justamente porque todas(os) interlocutoras(es) que se abriram ao convite para participar indicaram convencimento a respeito do papel "definidor" que os profissionais da saúde teriam (e têm) sobre questões "fundamentalmente orgânicas".

Importante lembrar que o método ABA, fortemente recomendado pela neurologista, foi registrado como eficiente nos comentários escolares "porque fundamentado em termos médicos".

A psicóloga destacou muito a importância de sistematizar dados para formação de professores e destacou que em sua avaliação a escola se "encontrava sobrecarregada". E a fonoaudióloga ressaltou que a escola nunca sabe o que as crianças com TEA preferem afirmando, como exemplo, que não gostam de atividades no papel. As ciências da saúde, em muitas falas, têm a prerrogativa de enumerar predileções subjacentes a todo e qualquer caso descrito no TEA.

Nesse aspecto, despontou uma ressignificação do cuidador. O diálogo com essa profissional da saúde deixou entrever o uso da categoria "ponto de referência". E, nesse sentido, o cuidador pareceu ser descrito como "novo e necessário ponto de referência" para a pessoa do TEA, tornando-se responsável por fazer a mediação entre professora e criança.

A dicotomia entre cuidar e educar se repunha seguidamente, especialmente porque os argumentos reiteravam a ideia de que os direitos derivados da contribuição que os saberes clínicos aferiam, constatavam, descreviam e prescreviam eram direitos relacionados ao cuidado. Projetavam os saberes docentes como tecnicamente prontos, dependentes apenas de alunas(os) desimpedidas(os) de "suas próprias amarras".

Despontavam imagens detalhadas com palavras como "neurotípicos", "normais" e representações de gênero bio referidas, como "meninas têm comunicação mais rápida", e essa base argumentativa se ancorava na convicção de que a ciência estava, ali, cumprindo seu papel. Mesmo assim, a neurologista confidenciou que acompanhou um menino que ela "jurava que era autista", mas que após alguns anos pode perceber que estava enganada. 


\section{Busca por outras perspectivas}

As dificuldades relacionadas à inclusão escolar de crianças diagnosticadas com TEA podem ser rapidamente associadas às dificuldades contidas na complexidade do autismo, em si. Trata-se, no entanto, de apressado e equivocado modo de reduzir a questão aos limites orgânicos que a proposta traz em seu bojo.

Há aspectos que dificultam sobremaneira a permanência de alunas(os) identificados com essa marca (GOFFMAN, 2010). Mas há, antes disso, aspectos derivados da maneira como a educação inclusiva tem sido assimilada e levada a efeito.

Rahme, Ferreira e Neves (2019) organizaram importante e denso dossier com o objetivo de analisar a então recente celebração, em 2018, da primeira década da Política Nacional de Educação Especial na Perspectiva da Educação Inclusiva, promulgada, como se sabe, em 2008.

Nesse rico material são muitas as oportunidades de se entender e analisar a facilidade com a qual engendramos estratégias segregadoras e como, em nome do inevitável ou do melhor possível, o papel articulador esperado das ações especializadas com seus respectivos espaços se esvanece.

A noção de público-alvo muitas vezes foi (e é) parte dos problemas enfrentados, não das soluções. Se aparentemente é impraticável abrir mão desse critério, a pesquisa no chão da escola tem demonstrado que é com esse critério que a "reivindicação de anormalidade" tem preservado sua força, inclusive com aportes judiciais.

Rahme (2014) já havia abordado a complexidade da presença autista, analisando na perspectiva do "laço social" as dimensões do "encontro com o outro". E poucos atores têm experimentado a dinâmica da alteridade radical com tanta intensidade. Testemunhamos essa condição de outro absoluto que se sobrepõe à criança autista, ou a criança diagnostica "n'algum lugar do TEA".

Em cada uma das partes dessa produção acadêmica é possível encontrar argumentos para demonstrar que é um erro considerar que educação inclusiva possa ser a educação especial bem-feita. A educação inclusiva supôs (ou supõe) que há limites na acepção de público-alvo e que a desconsideração de aspectos interseccionados na vida concreta abre espaço para a recriação permanente do binarismo normal versus anormal. Assim, aparentemente, sempre o 
que falta é comprovar a veracidade daquilo que descreve o "incapaz, como incapaz".

Pimenta (2019) indaga se não seria a caixa de ferramentas da psicanálise mais adequada para enfrentar os desafios analíticos e operacionais da permanência, relativizando tudo o que tem sido descrito no CID-108. Em suas palavras: "Para um psicanalista, a criança com autismo não sofre de um déficit perceptivo ou de uma falha cognitiva, mas de um excesso - excesso da presença do outro, a qual tem que anular" (PIMENTA, 2019, p.12).

A autora associa possibilidades de deslocamento dentro do chamado espectro, buscando maior abertura ao esforço para oferecer a estruturação de uma "borda que protege o sujeito" (PIMENTA, 2019, p.15).

Mas tais abordagens sequer conseguem se aproximar do cotidiano escolar quando se interpõe a percepção de que a deficiência é algo em si e que, por isso, a pessoa é uma decorrência dela. Os modos particulares de participar da experiência passam a ser registros de ausência, de não presença.

Para isso, não há fármaco que dê conta dos desencontros entre instituição e pessoa e as vantagens obtidas com o reconhecimento da deficiência se tornam aquilo que Martínez e Rey (2017) denominam "salvo conduto para a não educação". Nesses termos, torna-se compreensível (mas nunca justificável) a percepção de que a "professora da criança diagnosticada é a sua cuidadora".

\section{Considerações finais}

O objeto deste artigo configurou-se com questões que ganharam sentido na aproximação que caracteriza os esforços etnográficos de observação e interpretação de cenários específicos, com suas cenas desafiadoras (GOFFMAN, 2011).

De perto, por dentro, submersos no cotidiano que observávamos, foi possível perceber a reiteração constante de um modo singular de evocar direitos entendidos como inerentes à educação inclusiva.

Esse modo singular de apropriação de direitos nos proporcionava perguntar, considerando que presenciamos repetitiva acumulação, se aquelas reivindicações, ora expressas

${ }^{8} \mathrm{CID}$ é o Código Internacional de Doenças, que se encontra na décima edição. 
por familiares, ora por professoras(es), ora por profissionais da saúde, não estariam engendrando, novamente, dicotomias entre educar e cuidar.

Como em quase todas as situações a presença de crianças diagnosticadas com TEA reduziu a expectativa de inclusão à esperança de acesso a cuidadoras(res), tornou-se muito palpável a advertência expressa por Martinez e Rey (2017) que demonstram o quanto é contraditório reivindicar educação, prescindindo dela.

Temos uma realidade complexa, já apreendida pela astúcia de mercado, que em tudo colabora para que professoras(res) se sintam sobrecarregadas(os) e sem respaldo. $O$ acesso docente à criança diagnosticada, gradualmente, é dificultado por mediações e mediadores que, na maioria dos casos, materializam um espaço dentro do espaço escolar, um território para a criança diagnosticada permanecer com "sua professora" enquanto as/os demais estudam.

A resposta é sim. Engendramos, com as respectivas ressignificações, mais uma vez a dicotomia entre educar e cuidar. Essa dicotomia atualiza a imagem dos "excluídos no interior" de Bourdieu (2005) e permite, também, responder à questão que, nesses contextos, se formula com base nas premissas de Erving Goffman (2010, 2012).

Goffman argumenta que em termos relacionais, nos jogos que configuram alguém como "apontável", ou seja, o ente passivo da estigmatização, é possível perceber que as protagonistas dessas tramas estabelecem condutas muitas vezes baseadas nas expectativas que têm a respeito da pessoa apontada.

Essas expectativas quase sempre precedem a própria pessoa e, não raro, pouco se referem à personagem concreta. Dizem respeito àquilo que já se sabe sobre o "conteúdo apontável". Aquilo que o autor denomina identidade real, pouco representa, porque já se sabe tudo o que o outro não é.

Por isso, num contexto permeado pela centralidade que o laudo adquiriu, um tecido social alinhavado com argumentos periciais, tornou-se possível reconhecer em muitas falas um conteúdo virtual, descrevendo uma identidade igualmente virtual, apontável "em qualquer situação em que o autismo esteja" (Mãe de aluna).

Fez-se necessário responder que sim à questão que também apresentamos ao início, ou seja, estamos construindo socialmente identidades que prescindem das pessoas em si, e porque são virtuais se distanciam das identidades reais. 
Escutamos muitas pessoas. Presenciamos interações as mais diversas. Excetuando a entrada em cena de agentes empresariais, verdadeiros mercadores de terapias, todas as demais personagens das tramas acompanhadas transpareciam aflito desejo de acertar e, em suas palavras, "incluir de verdade".

Se essa é uma trama que agregou à escola inúmeros coadjuvantes, cabe reforçar e retomar o protagonismo docente no enfrentamento pedagógico do enorme desafio em questão. Sem esse protagonismo a educação inclusiva perde forma e conteúdo.

\section{Referências}

ALMEIDA, M. A.; MENDES, E. G.; HAYASHI, M. C. P. I. (orgs.). Temas em educação especial: múltiplos olhares. Araraquara: Junqueira \& Marin; Brasília: CAPES-PROESP, 2008.

ALVES, M. D. Alunos com autismo na escola: um estudo de práticas de escolarização. 2014. 143f. Tese (Doutorado em Educação) - Programa de Pós-Graduação em Educação, Universidade do Vale do Rio dos Sinos, São Leopoldo, 2014.

BARRETO, M. I. C. Emergências no processo de interação da criança com transtorno do espectro autista: um estudo de caso em Salvador/Bahia. 2016. 105f. Tese (Doutorado em Educação) Programa de Pós-Graduação em Educação, Universidade Federal da Bahia, Salvador, 2016.

BOURDIEU, P. A miséria do mundo. Petrópolis, Editora Vozes, 2005.

BRASIL, Declaração de Salamanca e linha de ação sobre pessoas com necessidades especiais. Brasília: Corde, 1994.

BRASIL. Conselho Nacional de Educação, Câmara de Educação Básica. Parecer no 17/2001. Apresenta Diretrizes Nacionais para a Educação Especial na Educação Básica, Brasília, DF, 2001.

BRASIL. Ministério da Educação. Institui Diretrizes Nacionais para a Educação Especial na Educação Básica. Brasília, DF, 2001.

BRASIL. Ministério da Educação. Secretaria de Educação Especial. Programa Educação Inclusiva: direito à diversidade. Brasília, DF: 2003.

BRASIL. Ministério da Educação. Secretaria de Educação Especial. Edital n.1, de 26 de abril de 2007. Programa de implantação de salas de recursos multifuncionais. Brasília, DF, 2007.

BRASIL. Lei no 4095 do Distrito Federal, de 01 de fevereiro de 2008. Assegura atendimento psicopedagógico aos estudantes com dislexia. Câmara dos Deputados: DF, 2008a. 
BRASIL. Ministério da Educação. Secretaria de Educação Especial. Política Nacional de Educação Especial na Perspectiva da Educação Inclusiva. Brasília, 2008b.

BRASIL. Decreto n.6.949, de 25 de agosto de 2009. Promulga a Convenção Internacional sobre os Direitos das Pessoas com Deficiência e seu protocolo facultativo, assinados em Nova York, em 30 de março de 2007. 2009a.

BRASIL. Conselho Nacional de Educação. Câmara de Educação Básica. Resolução CNE/CEB n.o 4, de 2 de outubro de 2009. Institui diretrizes operacionais para o atendimento educacional especializado na educação básica, modalidade educação especial. Diário Oficial da União, 5 de outubro de 2009, 2009b.

BRASIL. Decreto № 7.612, Presidência da República, Plano Nacional dos Direitos da Pessoa com Deficiência: viver sem limites, Diário Oficial da União, 17 de novembro de 2011, 2011.

BRASIL. Lei $n^{\circ}$ 12.764, de 27 de dezembro de 2012. Institui a Política Nacional de Proteção dos Direitos da Pessoa com Transtorno do Espectro Autista; e altera o $\$ 3^{\circ}$ do art. 98 da Lei no 8.112, de 11 de dezembro de 1990. 2012.

BRASIL. Lei no 13.146, de 6 de julho de 2015. Dispõe sobre a Lei Brasileira de Inclusão da Pessoa com Deficiência, Câmara dos Deputados, DF, 2015.

CANGUILLEM, G. O normal e o patológico. Rio de Janeiro, Zahar Editora, 2000,

CERTEAU, M. A invenção do cotidiano. Petrópolis, Editora Vozes, 2000.

FERREIRA, L.; LOWENKRON, L. Etnografia de documentos: pesquisas antropológicas entre papéis, carimbos e burocracias. Rio de Janeiro: E-papers, 2020.

FREITAS, M. C. De diagnósticos e prognósticos: crianças com experiências de escolarização em processos de isolamento, internação e hospitalização. Relatório de Pesquisa. Brasília: CNPq, 2017.

FREITAS, M. C.; BICCAS, M. S. História social da educação no Brasil. São Paulo: Cortez, 2009.

FREITAS, M. C.; GARCIA, E. C. De diagnósticos e prognósticos: laudos na configuração de muitas experiências de escolarização. Cadernos de Pesquisa, Fundação Carlos Chagas, v.49, p.316-340, 2019.

FREITAS, M. C.; PRADO, R. L. C. O professor e as vulnerabilidades infantis. São Paulo: Cortez, 2017.

GOFFMAN, E. Reader Goffman. Chicago: University of Chicago Press, 2011.

GOFFMAN, E. Estigma. Rio de Janeiro: LTC, 2010. 
GOFFMAN, E. Interação face a face. Petrópolis: Vozes, 2012.

GOMES, C. G. S.; MENDES, E. G. Escolarização inclusiva de alunos com autismo na rede municipal de ensino de Belo Horizonte. Revista Brasileira de Educação Especial, v.16, n.3, p.375-396, dez. 2010.

GONÇALVES, R. B. A presença de crianças diagnosticadas com autismo na rede pública de ensino. 2019. 168f. Dissertação (Mestrado em Educação) - Programa de Pós-Graduação em Educação, Unifesp, Guarulhos, 2019.

LAHIRE, B. Sucesso escolar nos meios populares: razões do improvável. São Paulo: Ática 2000.

LIMA, S. M.; LAPLANE, A. L. F. Escolarização de alunos com autismo. Revista Brasileira de Educação Especial, Marília, v.22, n.2, p.269-284, abr./jun. 2016.

LÓPEZ, M. La falacia de la conjunción y la contextualización en el autismo. Estudios Pedagógicos Valdivia, v.37, n.1, p.279-291, 2011.

LUZ, K.C. Veiculação da produção científica sobre o autismo no Brasil: embates e tensões. In: BUENO, J. G. S. et al. (orgs). A produção do conhecimento no campo da educação especial. Araraquara: Junqueira e Marin, 2018.

MARTINEZ, A. M.; REY, F. G. Psicologia, educação e aprendizagem escolar. São Paulo, Cortez Editora, 2017.

MELO, S.C. Inclusão em educação: um estudo sobre as percepções de professores da rede estadual de ensino fundamental do Rio de Janeiro, sobre práticas pedagógicas de inclusão, a partir de um caso de autismo. 2010. 220f. Tese (Doutorado em Educação) - Programa de PósGraduação em Educação, Universidade Federal do Rio de Janeiro, Rio de Janeiro, 2010.

NEVES, A. J.; ANTONELLI, C. S.; SILVA, M. G. C.; CAPELINI, V. L. M. F. Escolarização formal e dimensões curriculares para alunos com autismo: o estado da arte da produção acadêmica brasileira. Educação em Revista, v.30, n.2, p.43-70, jun. 2014.

ORGANIZAÇÃO DAS NAÇÕES UNIDAS (ONU). Declaração dos Direitos das Pessoas Deficientes, 2006. Disponível em: http://portalmec.gov.br/seesp/arquivos/pdf/dec_def.pdf. Acesso em: 24 jan. 2019.

PIMENTA, P.R. Clínica e escolarização dos alunos com transtorno do espectro do autismo (TEA). Educação \& Realidade, Porto Alegre, v.44, n.1, p.1-22., 2019.

RAHME, M.M.F. Laço social e educação: um estudo sobre os efeitos do encontro com o outro no contexto escolar. Belo Horizonte: Fino Traço, 2014.

RAHME, M. M. F.; FERREIRA, C. M. R. J.; NEVES, L. R. Sobre educação, política e singularidade. 
Educação \& Realidade, Porto Alegre, v.44, n.1, p 1-13, 2019.

SÃO PAULO. Lei 12.524/07. Dispõe sobre a criação do Programa Estadual para Identificação e Tratamento da Dislexia na rede oficial de ensino. Assembleia Legislativa: SP, 2007.

SENNETT, R. Juntos. Rio de Janeiro: Record, 2013.

Recebido em junho 2020.

Aprovado em fevereiro 2021. 